SHORT COMMUNICATION

\title{
Evaluation of Morphometric Measurements to Estimate Body Weight in Crossbred Landly Pigs (Landrace* Desi)
}

\author{
Anjali Kumari ${ }^{1}$, Triveni Dutt ${ }^{2}$, Amit Kumar ${ }^{3}$, M.R. Verma ${ }^{4}$ and Rupasi Tiwari ${ }^{5}$ \\ ${ }^{1}$ Department of Livestock Production Management, ICAR-IVRI, Bareilly, U.P., INDIA \\ ${ }^{2} I C A R$-Indian Veterinary Research Institute, Bareilly, U.P., INDIA \\ ${ }^{3}$ Department of Animal genetics and breeding, ICAR-IVRI, Bareilly, INDIA \\ ${ }^{4}$ Livestock Economics, Statistics E Information Technology, ICAR-IVRI, Bareilly, U.P., INDIA \\ ${ }^{5}$ Division of Extension Education, ICAR-IVRI Bareilly, U.P., INDIA
}

"Corresponding author: A Kumari; E-mail:anjali8992@gmail.com

Received: 26 Sept., 2020

Revised: 14 Oct., 2020

Accepted: 05 Dec., 2020

\begin{abstract}
Weight is an important index in swine meat industry. Indirect method of weight measurement involves usage of body measurements. Heart girth is known to be better correlated with body weight in pigs. A study was carried out to determine the relationship between different girths like the heart girth (measured just behind the forelimbs), middle girth (measured around mid-region of the body) and tail girth (measured just in front of the hind limbs) and live weight in Landly pigs (Landrace* Desi). Data was collected for body length, girths, and live weight in 39 pigs, both male and female and 9-10 months of age, reared in the IVRI Swine farm. Multiple linear regression method was used for analysis under GMP9. The results showed high positive correlations of weight with middle girth. Area calculated using middle girth and heart girth had the best fit and the lowest error. This can be applicable to pigs reared under field conditions.
\end{abstract}

\section{HIGHLIGHTS}

(0 Usage of different girths for prediction of body weights in pigs.

(0 Middle girth alone and in combination with heart girth provides best estimation of body weight.

Keywords: Pig, measurements, girth, weight, prediction

Pig meat is the second most popular meat source accounting for $38 \%$ of meat production worldwide (apeda.gov.in). In India, pig population comprises of $1.69 \%$ of the total livestock population (dahd, $20^{\text {th }}$ livestock census, 2019). According to FAO "Meat Market review - Overview of global meat market developments in 2018", world pig meat output is 120.5 million tons with china leading with $46 \%$ of the world output (fao.org). In meat production weight is an indispensable index and feed accounts for $60 \%$ of production costs. Accurate calculation of feed requirement depends on accurate calculation of weight (Brandl and Jørgensen, 1996). Besides this, accurate estimation of the live weight of slaughter pigs is significantly useful to the farmer in many ways. Not only does it determines the state of maturity for market but also enables the farmer to ascertain the ideal time to send his pigs for slaughter (Stygar and Kristensen, 2016). Monitoring pig weights on a regular basis provides direct assessment of health and growth state of the pigs. Emerging diseases, environmental issues in the herd, or issues with the feed formulation which can manifest in the form of reduced growth rate can be detected with ease (Jensen and Kristensen, 2017). Direct and indirect are the two methods of weighing. Direct method involves weighing the animals manually.

How to cite this article: Kumari, A., Dutt, T., Kumar, A., Verma, M.R and Tiwari, R. (2020). Evaluation of morphometric measurements to estimate body weight in crossbred Landly pigs (Landrace*Desi). J. Anim Res., 10(6): 1099-1102. 
Though it provides the most accurate weight yet has the associated potential to cause injury and is stressful to both the animal and the handler. Other disadvantages include high labour, requirement, and weight loss due to changes in feeding behaviour of pigs. Also, the constant physical contact of the weighing machine with the animal and the dirty environment may lead to inaccuracies (Brandl and Jørgensen, 1996). On the other hand, the indirect method involves estimation of weight visually, usage of linear body measurements, and analysis of images (Zaragoza, 2009). Many farms or small scale farmers lack a scale, especially in developing countries. Thus, regression models have been developed to indirectly estimate body weight using body measurements (Walugembe et al., 2014).The heart girth, body length, height at withers, and flank-flank measurements have been major measurements used in weight estimation. Many studies conducted in the past have already established the fact that heart girth is best correlated with body weight in pigs (Groesbeck et al., 2004; Sungirai et al., 2014) and height is not a fairly good estimator of weight (Machebe, and Ezekwe, 2016).Here in this study we are trying to determine the relationship of different girths (heart girth, middle girth, tail girth) with weight in Landly (Landrace * Desi) pigs and find out whether girths other than heart girth have any contribution in weight prediction.

The study was carried out at Swine farm of Livestock Production Management Section at Indian Veterinary Research Institute, Izatnagar, Uttar Pradesh. It falls in India's upper Gangetic plain region and has a humid subtropical climate

Thirty nine Landly (Landrace * Desi) pigs both male and female, of age group i.e. 9-15 months were selected. The pigs were kept in loose housing system, male and females grouped separately with each group comprising 5 pigs. Pigs of the same litter were kept together. Animals' nutritional requirements were met through a balanced concentrated feed mixture. Vaccination was done routinely for all the important diseases. Feeding and housing management of the selected pigs were kept constant. Recording was done every weekend in the month of August (2019).

Animal was restrained in a crate in the morning (8-10 a.m.) before feeding. A cloth measuring tape was used to take measurements which were recorded manually in metric units (Fig. 1). Length (L) was taken as the length from the base of the neck to the base of the tail. Then the tape was placed directly behind the front legs and heart girth was taken as the circumference of the chest area just behind the forelegs. Middle girth (MG) was the circumference measured at the middle part of the body of pig while tail girth (TG) was measured in the hind region with tape placed directly in-front of the hind legs. Height (H)was measured from the highest point just behind the neck to the ground level. Later, the animals were moved to the electronic weighing platform to record their actual weight. The information was collected on data sheets and then entered into the Microsoft Excel spreadsheet.

Once the data was entered into the Microsoft Excel Spreadsheet, errors and inconsistencies in data collection were addressed. Statistical analysis was performed using GMP9. Karl Person Correlation coefficient was calculated as given in equation (1) to determine which single body measurement or the combination is best correlated with body weight.

$$
r=\frac{\sum_{t=1}^{n}\left(x_{t}-\bar{x}\right)\left(y_{t}-\bar{y}\right)}{\sqrt{\sum_{t=1}^{n}\left(x_{t}-\bar{x}\right)^{2} \sum_{t=1}^{n}\left(y_{t}-\bar{y}\right)^{2}}}
$$

where $x_{t}, y_{t}$ are observed values at time $t, \bar{x}$ is mean of $x, \bar{y}$ is mean of $y$, and $n$ is the number of observations. The regression analysis was done by regressing the body measurements on the body weight and prediction equations were generated. The Coefficient of determination $\left(R^{2}\right)$ also known as goodness of fit was used to analyse how well the regression prediction model fits the observed data. $\mathrm{R}^{2}$ was computed as per equation (2), where $\hat{\mathrm{Y}}$ is the estimated value.

$$
R^{2}=1-\frac{\sum_{t=1}^{n}\left(y_{t}-\hat{y}\right)^{2}}{\sum_{t=1}^{n}\left(y_{t}-\bar{y}\right)^{2}}
$$

Adjusted $R^{2}$ describes the effect of multiple predictor variables on weight and its estimation is depicted in equation (3) where $k$ is the number of predictor or independent variables and $n$ is the number of observations.

$$
\text { Adjusted } R^{2}=1-\frac{\left(1-R^{2}\right)(n-1)}{n-k-1}
$$


RMSE value was calculated to identify the error in prediction using equation 4 .

$$
\mathrm{RMSE}=\sqrt{\sum_{i=1}^{n} \frac{\left(\hat{y}_{i}-y_{i}\right)^{2}}{n}}
$$

Regression analysis (table 1) indicated that weight in pigs is best correlated with heart girth $(r=0.89)$ and least correlated with height $(r=0.43)$. Heart girth is better correlated with length $(r=0.71)$ than with height $(r=0.49)$. Area calculated using heart girth and length produced the similar root mean square error $(\mathrm{RMSE}=11.91)$ as with heart girth alone.

Based on these preliminary results, to minimise any variation due to age difference, 23 pigs of age 9-10 months were selected from the group of 39 pigs. In this group, additional parameters such as middle girth and tail girth were also considered. Khanji et al. (2018) estimating the weight of marrãs explained that when the regression model studies other variables such as the body length, physiological state, thoracic perimeter, body score and fat thickness, more accurate results can be obtained. Weight estimation using regression in these animals (Table 2) indicated weight is best correlated with the cross sectional area calculated using middle girth (i.e. length* middle girth $^{2}$ ) with the highest correlation coefficient of 0.862 . Highest adjusted $\mathrm{R}^{2}$ value of $70.8 \%$ and lowest root mean square error of 8.24 was obtained. The three girths viz. heart girth, middle girth and tail girth were analysed for their mutual correlation. It revealed that middle girth and tail girth are best correlated with highest correlation coefficient of 0.870 . Cross sectional area was calculated using the combination of two different girths. Regression of weight on the area calculated indicated that best correlation of 0.884 and highest adjusted $\mathrm{R}^{2}$ of $75.4 \%$ is obtained when weight is regressed on cross sectional area calculated using product of length with heart girth and middle girth. RMSE value (root mean square error) of 7.59 was obtained which is lowest as compared to 8.48 and 8.50 obtained in the other two combinations. F statistic indicated that the observed $\mathrm{R}^{2}$ and adjusted $\mathrm{R}^{2}$ is reliable and is not a result of chance or oddities in the data set. The large $F$ statistic value of $144.026(\mathrm{P}<0.01)$ obtained in case of middle girth (Table 1$)$ and $37.783(\mathrm{P}<0.01)$ obtained in

Table 1: Regression of body weight on body measurements in Landly pigs (9-15 months old).

\begin{tabular}{llllllll}
\hline Sl. No. & $\begin{array}{l}\text { Independent } \\
\text { variables }\end{array}$ & $\mathbf{r}$ & F Statistics & Regression Equation & $\mathbf{R}^{2}$ & Adj R $^{2}$ & RMSE value \\
\hline 1 & $\mathrm{~L}$ & 0.760 & $49.614^{* *}$ & $\mathrm{~W}=-171.13+2.27^{* *} \mathrm{~L}$ & 0.580 & 0.568 & 17.1 \\
2 & $\mathrm{HG}$ & 0.890 & $144.026^{* *}$ & $\mathrm{~W}=-170.42+1.99^{* *} \mathrm{HG}$ & 0.800 & 0.794 & 11.8 \\
3 & $\mathrm{H}$ & 0.430 & $8.32^{*}$ & $\mathrm{~W}=-68.67+2.90^{*} \mathrm{H}$ & 0.188 & 0.165 & 23.8 \\
4 & $\mathrm{~L}, \mathrm{HG}^{2}$ & 0.890 & $84.664^{* *}$ & $\mathrm{~W}=-64.372+0.765^{*} \mathrm{~L}+0.006^{* *} \mathrm{HG}^{2}$ & 0.829 & 0.819 & 11.9 \\
\hline
\end{tabular}

$* \mathrm{P}<0.05 * * \mathrm{P}<0.01, \mathrm{r}$ is correlation coefficient, $\mathrm{R}^{2}$ is coefficient of determination, Adj. $\mathrm{R}^{2}$ is adjusted coefficient of determination, RMSE is root mean square error value, w is weight of pigs, $\mathrm{L}$ is body length of pigs, HG is heart girth, MG is middle girth, TG is tail girth.

Table 2: Regression of body-weight on body measurements in Landly pigs (9-10 months old)

\begin{tabular}{|c|c|c|c|c|c|c|c|}
\hline Sl. No & $\begin{array}{l}\text { Independent } \\
\text { variables }\end{array}$ & $\mathbf{r}$ & F Statistics & Regression Equation & $\mathbf{R}^{2}$ & $\operatorname{Adj} R^{2}$ & RMSE value \\
\hline 1 & $\mathrm{~L}, \mathrm{HG}^{2}$ & 0.860 & $29.605^{* *}$ & $\mathrm{~W}=-9.874+0.763 * \mathrm{~L}+0.007 * * \mathrm{HG}^{2}$ & 0.729 & 0.704 & 8.29 \\
\hline 2 & $\mathrm{~L}, \mathrm{MG}^{2}$ & 0.862 & $30.025 * *$ & $\mathrm{~W}=-63.228+0.734 * \mathrm{~L}+0.005 * * \mathrm{MG}^{2}$ & 0.732 & 0.708 & 8.24 \\
\hline 3 & $\mathrm{~L}, \mathrm{TG}^{2}$ & 0.803 & $22.929 * *$ & $\mathrm{~W}=-88.579+1.057 * \mathrm{~L}+0.005 * * \mathrm{TG}^{2}$ & 0.676 & 0.646 & 9.67 \\
\hline 4 & L, HGMG & 0.884 & $37.783 * *$ & $\mathrm{~W}=-67.097+0.680 * \mathrm{~L}+0.007 * * \mathrm{HGMG}$ & 0.775 & 0.754 & 7.59 \\
\hline 5 & L, HGTG & 0.852 & $29.281 * *$ & $\mathrm{~W}=-81.897+0.894 * \mathrm{~L}+0.006^{* *} \mathrm{HGTG}$ & 0.727 & 0.702 & 8.50 \\
\hline 6 & L, MGTG & 0.860 & $28.874 * *$ & $\mathrm{~W}=-78.588+0.887 * \mathrm{~L}+0.005 * * \mathrm{MGTG}$ & 0.724 & 0.699 & 8.48 \\
\hline
\end{tabular}

$* \mathrm{P}<0.05^{* *} \mathrm{P}<0.01, \mathrm{r}$ is correlation coefficient, $\mathrm{R}^{2}$ is coefficient of determination, Adj. $\mathrm{R}^{2}$ is adjusted coefficient of determination, RMSE is root mean square error value, $w$ is weight of pigs, $\mathrm{L}$ is body length of pigs, HG is heart girth, MG is middle girth, TG is tail girth. 
the combination of middle and heart girth (Table 2) means that, the predictor variables are significantly related to the outcome variable i.e. weight. Clearly, of the three girths, middle girth can better elucidate body weight both when used alone or when used in combination with heart girth. This may be due to the fact that the whole thoracic area of pig is taken into account which carries the maximum weight. Application of this can prove useful to farmers in field conditions where measuring balance is not available.

\section{CONCLUSION}

Middle girth can explain body weight in pigs with greater precision. Also the weight of the pigs is jointly explained by area calculated using middle girth and heart girth. Further, results can be improved though new studies involving more morphometric characteristics and finding their association with animal weight.

\section{ACKNOWLEDGMENTS}

The research was supported by the scholarship under CAAST-ACLH, NAHEP.

\section{REFERENCES}

Brandl, N. and Jørgensen, E. 1996. Determination of live weight of pigs from dimensions measured using image analysis. Comput. Electron. Agric., 15(1): 57-72.

Groesbeck, C.N., Lawrence, K.R., Young, M.G., Goodband, R.D., DeRouchey, J.M., Tokach, M.D., Nelssen, J.L. and Dritz, S.S. 2002. Using heart girth to determine weight in finishing pigs, pp. 166-168.
http://dadf.gov.in/sites/default/filess/BAHS (Basic Animal Husbandry Statistics-2019).

http://www.fao.org/3/ca3880en/ca3880en "Overview of global meat market developments in 2018" March 2019.

Khanji, M.S.A.L.A., Liorente, C., Falceto, M.V., Bonastre, C., Mitjana, O. and Tejedor, M.T. 2018. Using body measurements to estimate body weight in gilts. Can. J. Anim. Sci., 98(2): 362-367.

Machebe, N.S. and Ezekwe, A.G. 2010. Predicting body weight of growing-finishing gilts raised in the tropics using linear body measurements. Asian J. Exp. Biol. Sci., 11: 162-165.

Stygar, A.H. and Kristensen, A.R. 2016. Monitoring growth in finishers by weighing selected groups of pigs-a dynamic approach. Anim. Sci. J., 94(3): 1255-1266.

Sungirai, M., Masaka, L. and Benhura, T.M. 2014. Validity of weight estimation models in pigs reared under different management conditions. Vet. Med. Int., 1-5.

Walugembe, M., Nadiope, G., Stock, J.D., Stalder, K.J., Pezo, D. and Rothschild, M.F. 2014. Prediction of live body weight using various body measurements in Ugandan village pigs. Livest. Res. Rural Dev., 26: 1-7.

Zaragoza, L.E.O. 2009. Evaluation of the accuracy of simple body measurements for live weight prediction in growingfinishing pigs [M.S. thesis], Graduate College of the University of Illinios Urbana Champaign. 